\title{
De plaats van kunstobservatie in de opleiding geneeskunde in Nederland
}

\author{
Maud Reijntjes · Pien de Ruiter · Lex Linsen · Mieke Derickx · Frank Willem Jansen · Sandrine van Noort • \\ Sabrina Kamstra - Thomas van Gulik - Gabor Linthorst
}

Samenvatting Kunstobservatie in de opleiding geneeskunde bevordert het observatievermogen en de sociaal-emotionele vaardigheden van studenten. Wij onderzochten de plaats van kunstgerelateerd onderwijs in de geneeskundefaculteiten in Nederland. Zes van de acht geneeskundefaculteiten in Nederland hebben een vorm van kunstobservatie in het curriculum opgenomen. In de twee overige faculteiten is deze vorm van kunstonderwijs in ontwikkeling. De vorm, duur en verplichting van dit onderwijs verschillen tussen de geneeskundefaculteiten. Onderzoek naar de uitkomsten van kunstobservatie is schaars. Lan-

Maud Reijntjes en Pien de Ruiter zijn gedeeld eerste auteur.

M. Reijntjes · P. de Ruiter · T. van Gulik ( $\bowtie)$

Afdeling Chirurgie, Amsterdam UMC, locatie AMC, Amsterdam, Nederland

t.m.vangulik@amsterdamumc.nl

L. Linsen

Afdeling Klinische technologie, Erasmus MC, Rotterdam, Nederland

M. Derickx

Faculty of Health Medicine and Lifesciences, Vakgroep

Health Promotion, Universiteit Maastricht, Maastricht, Nederland

F. W. Jansen

Afdeling Gynaecologie, Leiden LUMC, Leiden, Nederland

S. van Noort

Afdeling Kunstzaken, Leiden LUMC, Leiden, Nederland

S. Kamstra

Afdeling Kunstzaken, Amsterdam UMC, locatie AMC,

Amsterdam, Nederland

G. Linthorst

Afdeling Inwendige geneeskunde, Amsterdam UMC, locatie AMC, Amsterdam, Nederland delijke samenwerking biedt kansen gezamenlijk het effect te bepalen van kunstobservatie op analytische en observationele vaardigheden van studenten.

Trefwoorden medische humaniora $\cdot$ medisch onderwijs · observationele vaardigheden $\cdot$ beeldende kunsten $\cdot$ kunstgerelateerd onderwijs

\section{The place of art observation in the medical curriculum in the Netherlands}

\begin{abstract}
Art observation enhances observational skills and social-emotional competences of students following a medical curriculum. We examined the impact of art-based education in the medical faculties in the Netherlands. Six out of eight faculties in the Netherlands implemented any form of art observation in their curriculum. In two faculties, application of art education in the teaching program is in progress. The design, duration, and mandatory participation differ between the faculties. Research assessing outcomes of art observation is scarce; nationwide collaboration of faculties offers opportunities to determine the effects of arts-based observation on analytical and observational skills of medical students.
\end{abstract}

Keywords Medical humanities - Medical education · Observation skills · Visual arts · Art-based learning

\section{Inleiding}

De opleiding geneeskunde in Nederland is voornamelijk gebaseerd op een kenniscurriculum. Het toepassen van kennis beoogt - ondersteund door technische hulpmiddelen - als een zo objectief mogelijk proces tot een diagnose te leiden. Het behandelvoorstel dat erop volgt, is een formele beslissing volgens geaccepteerde richtlijnen, liefst evidence-based. Zoals eerder 
in dit tijdschrift beschreven, komen voor een succesvolle diagnose en behandeling ook subjectieve waarneming en visie op de patiënt om de hoek kijken [1]. Patroonherkenning en het toelaten van ambiguïteit spelen hierin een belangrijke rol. Menselijke interactie en inlevingsvermogen in de patiënt zijn onmisbaar bij het tot stand komen van gezamenlijke besluitvorming en het verlenen van gepersonaliseerde zorg (shared decision making). Subjectieve, zintuigelijke waarnemingen zijn voor de arts cruciaal om samen met de patiënt een passend zorgplan op te kunnen stellen.

Terwijl medische basiskennis in het huidige geneeskundecurriculum wordt getoetst, is er tijdens de opleiding beperkt aandacht voor training van vaardigheden als het herkennen en interpreteren van patronen. Er wordt vanuit gegaan dat deze pas na jaren klinische ervaring verkregen worden. Vooral het (h)erkennen van de behoeften van de patiënt rond zijn of haar behandeling wordt steeds belangrijker, zodat samen met de patiënt tot een behandeling 'op maat' kan worden gekomen. Het bepaalt daarmee voor een belangrijk deel de kwaliteit van de zorgverlening. Kunstobservatie kan bijdragen aan het leren waarnemen van zowel subjectieve als objectieve elementen in de geneeskunde [2, 3].

Uit Amerikaans onderzoek is gebleken dat het kijken naar kunst observatievaardigheden kan verbeteren [4]. Ook nauwkeurig omschrijven, zonder direct oordeel, draagt bij aan verbetering van het diagnostisch vermogen [4]. Het gebruik hierbij van Arts-based learning en Visual Thinking Strategies - twee verschillende onderwijsmethoden waarin leren met beeldende kunst het uitgangspunt vormt - versterken het empathisch vermogen van een arts $[4,5]$. Door te reflecteren op het kijken naar kunst, leren studenten ook beter te reflecteren op zichzelf en verkrijgen ze inzicht in de vooroordelen die ze bewust en onbewust met zich meedragen [6, 7].

Hoewel het bewijs beperkt was, concludeerden Elbert et al. in 2013 op basis van literatuuronderzoek dat kunstobservatie door medisch studenten een positief effect leek te hebben op hun observatievaardigheden [8]. Na de publicatie van dit artikel zijn kwantitatieve onderzoeken verschenen die hebben bevestigd dat kunstgerelateerd onderwijs de observatievaardigheden van geneeskundestudenten kan bevorderen [4].

In Nederland is de belangstelling voor het toepassen van 'kunst' in de opleiding geneeskunde de laatste jaren toegenomen. Een aantal geneeskundefaculteiten heeft tot nu toe verschillende programma's ontwikkeld en geïntegreerd in het curriculum, op basis van eigen identiteit en lokale museale mogelijkheden. Wij inventariseerden de stand van zaken omtrent kunstgerelateerd onderwijs in de geneeskundefaculteiten in Nederland. Hiermee willen we een aanzet geven tot samenwerking, om door gemeenschappelijk onderzoek het effect te bepalen van kunstobservatie in de opleiding. Zo willen we op termijn bijdragen aan een structurele integratie van kunstonderwijs in het medisch curriculum.

\section{Methode}

We zochten in april 2020 naar publicaties (vanaf 2010) over kunstgerelateerd onderwijs aan geneeskundestudenten en medische professionals in Nederland in de databases van PubMed en de bestanden van het Nederlands Tijdschrift voor Geneeskunde, Medisch Contact en Nederlandse universitaire faculteitsbladen. Aan de hand van deze publicaties namen wij in mei en juni 2020 contact op met de initiatiefnemers en coördinatoren van het betreffende onderwijs in Rotterdam, Leiden, Maastricht, Nijmegen en Utrecht, waardoor wij per faculteit de aard van het kunstgerelateerde onderwijs in kaart konden brengen. Overleg met de faculteit in Groningen kon voor dit onderwerp niet worden gerealiseerd. We onderzochten de onderwijsvormen en de betrokken partijen uit de kunstvakken en de medische beroepsgroepen. Ook de omvang van het onderwijs, de hoeveelheid participerende studenten en docenten, frequentie, duur en studielast van de bijeenkomsten werden geïnventariseerd. Inhoudelijk keken we naar de gekozen aandachtsgebieden en centrale onderwerpen, de gebruikte kunstvormen, de leerdoelen en de gekozen onderwijsvormen. Ook onderscheidden we verplichte en facultatieve onderwijsvormen.

\section{Resultaten}

De bevindingen over het kunstgerelateerde onderwijs in de Nederlandse geneeskundefaculteiten zijn samengevat in tab. 1.

\section{Erasmus Medisch Centrum}

De verplichte werkgroep 'De kunst van het kijken' wordt sinds 2016 aangeboden aan tweedejaars bachelorstudenten in het Museum Boijmans van Beuningen. De werkgroep is gericht op klinisch redeneren en het verbeteren van observationele en communicatieve vaardigheden via het medium van de beeldende kunst.

Tijdens de twee uur durende werkgroep worden de studenten opgedeeld in werkgroepen, die volgens een vast programma langs dezelfde schilderijen worden geleid door een museumconservator en een arts. De werkopdracht bestaat uit twee onderdelen: een opdracht gericht op formele vormbeschrijving en één gericht op subjectieve beschrijving van een kunstwerk. Hiermee worden de verschillen tussen observeren en interpreteren voor de studenten inzichtelijk gemaakt en oefenen ze zich in de overdracht van informatie. Daarbij komt het thema 'ambiguïteit' aan bod: leren omgaan met onvolledigheid. Dit wordt als essentieel ervaren, omdat een arts niet altijd kan vertrouwen 
Tabel 1 Kenmerken en inhoudelijk overzicht van kunstgerelateerd onderwijs in de opleiding geneeskunde in Nederland

\begin{tabular}{|c|c|c|c|c|c|}
\hline & Erasmus MC & LUMC & Universiteit Maastricht & Radboudumc & UMCU \\
\hline \multicolumn{6}{|c|}{ kenmerken kunstgerelateerd onderwijs } \\
\hline vorm & werkgroep & honours class & keuzeblok & werkatelier & keuzecursus \\
\hline periode & 2016-heden & 2019-heden & 2017-2019 & 2016-heden & 2017-heden \\
\hline $\begin{array}{l}\text { intra-/ } \\
\text { extracurriculair }\end{array}$ & intracurriculair & extracurriculair & intracurriculair & extracurriculair & extracurriculair \\
\hline $\begin{array}{l}\text { aantal studen- } \\
\text { ten }\end{array}$ & 480 geneeskunde & 16 (8 geneeskunde) & 10-15 geneeskunde & 32 geneeskunde & 28 (2 geneeskunde) \\
\hline $\begin{array}{l}\text { academische } \\
\text { fase }\end{array}$ & Bachelor jaar 2 & Bachelor jaar 3 & Bachelor jaar 2 & Master & Bachelor jaar $1 / 2 / 3$ \\
\hline duur & $\begin{array}{l}1 \text { sessie } \\
\text { (2 uur/stuk) }\end{array}$ & $\begin{array}{l}9 \text { sessies } \\
\text { (2-3 uur/stuk) }\end{array}$ & 4 weken & $\begin{array}{l}7 \text { sessies } \\
\text { (8 uur/stuk) }\end{array}$ & $\begin{array}{l}3 \text { maanden } \\
\text { (4-6 uur/week) }\end{array}$ \\
\hline studielast & $\begin{array}{l}\text { laag, }<1 \text { EC } \\
\text { (=2 uur) }\end{array}$ & $\begin{array}{l}\text { hoog, } 5 \text { EC } \\
\text { (=140 uur) }\end{array}$ & $\begin{array}{l}\text { hoog, } 4 \text { EC } \\
\text { (=112 uur) }\end{array}$ & $\begin{array}{l}\text { gemiddeld } \\
\text { (circa } 50 \text { uur) }\end{array}$ & $\begin{array}{l}\text { hoog, } 7,5 \text { EC } \\
\text { (=210 uur) }\end{array}$ \\
\hline toetsing & $\begin{array}{l}\text { presentie en participatie, na- } \\
\text { bespreking na het uitvoeren } \\
\text { van opdrachten }\end{array}$ & $\begin{array}{l}\text { participatie, deeltoetsen en } \\
\text { eindopdracht: essay }\end{array}$ & $\begin{array}{l}\text { participatie, presentatie, } \\
\text { afsluiting weekthema's en } \\
\text { eindopdracht (essay) }\end{array}$ & $\begin{array}{l}\text { geen toetsing, evalua- } \\
\text { tie van inzichten aan } \\
\text { het einde van de dag }\end{array}$ & $\begin{array}{l}\text { participatie, portfolio, groeps- } \\
\text { presentaties }\end{array}$ \\
\hline \multicolumn{6}{|c|}{ inhoudelijk overzicht kunstgerelateerd onderwijs } \\
\hline thematiek & $\begin{array}{l}\text { verschillen tussen observeren } \\
\text { en interpreteren, perspectief } \\
\text { van kijken, ambiguitteit }\end{array}$ & $\begin{array}{l}\text { gezondheid, kunst in de } \\
\text { gezondheidszorg, kunst } \\
\text { voor de patiënt }\end{array}$ & $\begin{array}{l}\text { driehoek: kunst, genees- } \\
\text { kunde, zintuigen }\end{array}$ & $\begin{array}{l}\text { interactie tussen } \\
\text { kunstenaar en student }\end{array}$ & $\begin{array}{l}\text { narratieven in de geneeskunde } \\
\text { en reflectie op het menselijk } \\
\text { lichaam door middel van pu- } \\
\text { blieksdialogen }\end{array}$ \\
\hline $\begin{array}{l}\text { leerdoelen of } \\
\text { vaardigheden }\end{array}$ & $\begin{array}{l}\text { observeren, communiceren, } \\
\text { informatieoverdracht, klinisch } \\
\text { redeneren }\end{array}$ & $\begin{array}{l}\text { observeren, literatuur- } \\
\text { onderzoek, schrijven, } \\
\text { presenteren }\end{array}$ & $\begin{array}{l}\text { zintuigelijke waarneming, } \\
\text { observeren (subjectief, } \\
\text { objectief), zelfervaring, } \\
\text { tekenen }\end{array}$ & $\begin{array}{l}\text { observeren, patroon- } \\
\text { herkenning, creatief } \\
\text { denken, reflecteren }\end{array}$ & schrijven, zelfervaring \\
\hline disciplines & $\begin{array}{l}\text { kunstgeschiedenis, genees- } \\
\text { kunde }\end{array}$ & $\begin{array}{l}\text { (kunst)geschiedenis, beel- } \\
\text { dende kunst, architectuur, } \\
\text { filosofie en geneeskunde }\end{array}$ & $\begin{array}{l}\text { beeldende kunst, genees- } \\
\text { kunde }\end{array}$ & $\begin{array}{l}\text { beeldende kunst, } \\
\text { geneeskunde }\end{array}$ & $\begin{array}{l}\text { kunst, geesteswetenschap- } \\
\text { pen, sociale wetenschappen, } \\
\text { geneeskunde }\end{array}$ \\
\hline kunstsoorten & schilderkunst & $\begin{array}{l}\text { schilder- en tekenkunst, } \\
\text { architectuur, literatuur }\end{array}$ & schilder- en tekenkunst & $\begin{array}{l}\text { schilder-, teken- en } \\
\text { beeldhouwkunst, } \\
\text { fotografie }\end{array}$ & literatuur \\
\hline musea & $\begin{array}{l}\text { Museum Boijmans Van Beu- } \\
\text { ningen }\end{array}$ & Museum De Lakenhal & $\begin{array}{l}\text { Bonnefantenmuseum, } \\
\text { Marres Museum, Gal- } \\
\text { lo-Romeins Museum, Jan } \\
\text { van Eyk Academie }\end{array}$ & $\begin{array}{l}\text { Geen musea, maar } \\
\text { kunstenaarsateliers }\end{array}$ & $\begin{array}{l}\text { Rijksmuseum te Amsterdam } \\
\text { (2018) }\end{array}$ \\
\hline
\end{tabular}

op herkenning, maar ook onbevooroordeeld iets moet kunnen beschrijven.

\section{Leids Universitair Medisch Centrum}

Het LUMC beschikt over een kunstcollectie van zo'n 2600 kunstwerken, die een vruchtbare voedingsbodem vormt voor de Honours Class 'Kijken is de (genees)kunst'. De Honours Class vormt een extracurriculair programma dat sinds 2018 wordt aangeboden aan derdejaars bachelorstudenten. Het programma neemt studenten mee langs verschillende kunstwerken uit de kunstcollectie van het LUMC met het doel te leren observeren, reflecteren en interpreteren.

De Honours Class (tien weken) is opgebouwd uit colleges, werkgroepen, opdrachten, interviews en een museumbezoek aan Museum De Lakenhal in Leiden onder begeleiding van een kunsthistoricus en een arts, en is gericht op het leren kijken naar beeldende kunst. Inhoudelijk worden diverse thema's behandeld door docenten met een geneeskundige, kunsthistorische, architectonische, kunstzinnige en filosofische achtergrond. Onderwerpen als symboliek, iconografie en ziekte verbeeld in de kunst komen aan bod, naast de filosofie van het kijken naar kunst en de kunst van opmerkzaamheid door het beschouwen van details in de beeldende kunst. Een bezoek aan het atelier van een kunstenaar is onderdeel van het geheel. In het programma is ook aandacht voor het perspectief van de patiënt op de implementatie van kunst in zorginstellingen. Zo wordt binnen het concept van een 'healing environment' de beleving van kunst en architectuur door patiënten geanalyseerd. De Honours Class eindigt met de interpretatie en reflectie op getoonde kunstwerken in een thematisch ingerichte tentoonstelling in Galerie LUMC.

\section{Maastricht Universitair Medisch Centrum}

In samenwerking met de Universiteit Maastricht werd tussen 2017 en 2019 een vier weken durend keuzevak 'Maakt het beleven van kunst je een betere dokter?' aangeboden aan tweedejaars bachelorstudenten. Het keuzeblok onderzocht parallellen en verschillen tussen kunst en geneeskunde, en nam de studenten mee in een traject dat leidde tot verbreding en nieuwe per- 
spectieven op hun vakgebied. Het droeg hiermee bij aan de persoonlijke reflectie en ontwikkeling binnen de academische vaardigheden van studenten [1].

Het blok behandelde elke week een thema vanuit de driehoek kunst, geneeskunde en de zintuigen, met behulp van trainingen, onderzoek, workshops, lezingen en interviews. De geneeskunde werd hierin benaderd als een ambachtelijk vak, waarin verbetering van de observationele vaardigheden werd nagestreefd door de ontwikkeling van zintuigelijke vaardigheden. Aandacht werd besteed aan begrippen als objectiviteit, subjectiviteit en sensitiviteit, en de koppeling hiervan aan het diagnosticeren in de medische praktijk. Door het gehele blok liep een cursus anatomisch en modeltekenen. Dit programma kreeg wegens het uitblijven van financiering geen vervolg.

\section{Radboud Universitair Medisch Centrum}

Het keuzevak 'De kunst van kijken en zien voor de medische professie' wordt sinds 2016 aangeboden aan coassistenten in samenwerking met een vaste groep van deelnemende kunstenaars en vindt plaats op zeven zaterdagen [9]. De interactie tussen kunstenaar en student staat centraal in het keuzevak door het aanbieden van werkateliers en observatieopdrachten. Een vertaalslag naar de medische praktijk wordt gemaakt door artsen die in de werkateliers een coachende rol aannemen en zorgen voor de terugkoppeling naar de geneeskunde.

Het programma onderscheidt zich van andere programma's in Nederland doordat het zich direct richt op de kunstenaarspraktijk en niet op kunsthistorische achtergronden. De studenten worden door deze directe koppeling aan de kunstenaar op locatie gestimuleerd om buiten de bestaande kaders te denken. Vanuit de kunstenaars werd bijvoorbeeld het belang van eerst 'uitzoomen' en daarna pas 'inzoomen' benadrukt, om zo een volledig beeld te kunnen krijgen van patiënten in de spreekkamer. Het keuzevak biedt studenten de ruimte om te reflecteren op het medische beroep en het eigen observeren, denken en handelen.

\section{Universitair Medisch Centrum Utrecht}

Kunst wordt in twee hoedanigheden geïmplementeerd in het Utrechtse curriculum. Sinds 2017 wordt extracurriculair onderwijs over 'narratieven in de geneeskunde' aangeboden aan studenten geneeskunde en geesteswetenschappen. Hierbij komt bijvoorbeeld het ervaren van een fictief verhaal vanuit het perspectief van een kind of een psychiatrische patiënt aan bod. In 2018 bezocht een aantal medische disciplines het Rijksmuseum in Amsterdam. Deelnemers voerden hier verschillende observatieopdrachten uit, met als doel objectiever naar kunst te leren kijken. Daarbij organiseerde de 'Nieuwe Utrechtse school' tevens publieksdialogen, waarin dansers, muzikanten, filosofen en letterkundigen vanuit hun eigen perspectief een plenaire dialoog voeren over verschillende medische elementen.

\section{Universitair medisch centrum Groningen}

Het Universitair Medisch Centrum Groningen bood haar geneeskundestudenten naast een cursus anatomisch tekenen een excursie naar het Groninger en Universiteitsmuseum aan. Beeldende kunst was een onderdeel van het blok 'Medical humanities'. Deze activiteiten hebben geen vervolg gekregen. Informatieverstrekking vanuit het onderwijsbureau was ontoereikend, waardoor de faculteit Groningen niet kon worden opgenomen in de resultatentabel.

\section{Amsterdam Universitair Medisch Centrum (AMC en VUmc)}

Het Academisch Medisch Centrum (AMC) en het VU Medisch Centrum zijn in juni 2018 samengegaan in het Amsterdam Universitair Medisch Centrum (Amsterdam UMC). Het voornemen is om gezamenlijk kunstgerelateerd onderwijs in de opleiding geneeskunde op te zetten. Op de locatie AMC wordt een programma ontwikkeld waarin het 'kijken naar kunst' een plaats krijgt in het geneeskundecurriculum, waarbij de aanwezige collectie, bestaande uit ruim 6.500 werken beeldende kunst, actief wordt ingezet. De geneeskundefaculteit van het Amsterdam UMC, locatie VUmc, ontwikkelde in 2017 samen met het Rijksmuseum een conceptprogramma dat tot doel had de kijk- en overdrachtsvaardigheden van geneeskundestudenten te verbeteren. Tevens werd voor honoursstudenten in samenwerking met de Rietveld Academie een werkgroep Creative writing georganiseerd en werd jaarlijks een symposium 'Literatuur en geneeskunde' gehouden. Beide faculteiten werken nu samen aan een extracurriculair vervolg op het programma voor honours-studenten geneeskunde in Amsterdam.

\section{Beschouwing}

We inventariseerden het kunstgerelateerde onderwijs in de geneeskundefaculteiten in Nederland. De meeste faculteiten hebben zelf een manier gevonden om afhankelijk van eigen kernwaarden, interne organisatie en beschikbaar budget, aandacht te geven aan kunstobservatie in het curriculum. Hoewel de invulling van kunst in het onderwijsprogramma per faculteit verschilt, weerspiegelt het brede aanbod van kunstgerelateerd onderwijs in Nederland de belangstelling die voor dit onderwerp bestaat. Deze inventarisatie biedt een overzicht van de kernwaarden die de faculteiten hanteren in het huidige aanbod van kunstgerelateerd onderwijs waarin het observeren en analyseren van beeldende kunst centraal staan. Samenwerking tussen de groepen die zich hiermee in de faculteiten bezighouden, biedt de mogelijkheid ken- 
nis en ervaring met deze vorm van kunstgerelateerd onderwijs te delen.

Hoewel in de internationale literatuur met behulp van objectieve methoden is aangetoond dat kunstobservatie in de opleiding geneeskunde een positieve invloed heeft, is hard bewijs hiervoor nog moeilijk te leveren. De vraag of we betere artsen opleiden door hen naar kunst te leren kijken, blijft dan ook lastig te beantwoorden. Het objectiveren van het analytisch en observationeel vermogen van deelnemers aan kunstgerelateerd onderwijs is in dit verband gewenst. Samenwerking tussen de Nederlandse faculteiten geeft de mogelijkheid om een onderzoek op te zetten waarin het effect van kunstgerelateerd onderwijs kan worden geëvalueerd. Gestandaardiseerde uitkomstmaten als reflectief vermogen, omgaan met ambiguïteit en het onderkennen van persoonlijke bias, kunnen worden geobjectiveerd door middel van gevalideerde pre- en posttestscores [10]. Daarnaast wordt kwalitatief onderzoek aanbevolen, in de vorm van een analyse van interviews met open vragen naar de ervaringen van de betrokken geneeskundestudenten [7]. Aangezien alle deelnemende groepen ervaring hebben met een vorm van museumbezoek met bespreking van een of meer kunstwerken, lijkt de 'museumomgeving' in dit verband het best toepasbaar. Evaluatie vindt gezamenlijk plaats met gelijke uitkomstmaten. Op deze manier kan een volgende stap worden gezet in het bepalen van het effect van kunstobservatie in de opleiding geneeskunde. Op termijn kan dan een breder draagvlak worden gecreëerd voor het gestructureerd integreren van kunstgerelateerd onderwijs in het geneeskundecurriculum.

Dankbetuiging Wij danken Annet van Royen voor haar informatie over kunstgerelateerd onderwijs in het UMC Utrecht. Noortje Bijvoets, Pauline Kintz (Rijksmuseum Amsterdam), Norbert Middelkoop en Miriam Sneeuwloper (Amsterdam Museum) danken wij voor de gedachtewisseling over kunstonderwijs in het museum. Wij danken Let Geerling voor haar kritische opmerkingen over het manuscript.

Open Access This article is licensed under a Creative Commons Attribution 4.0 International License, which permits use, sharing, adaptation, distribution and reproduction in any medium or format, as long as you give appropriate credit to the original author(s) and the source, provide a link to the Creative Commons licence, and indicate if changes were made. The images or other third party material in this article are included in the article's Creative Commons licence, unless indicated otherwise in a credit line to the material. If material is not included in the article's Creative Commons licence and your intended use is not permitted by statutory regulation or exceeds the permitted use, you will need to obtain permission directly from the copyright holder. To view a copy of this licence, visit http://creativecommons.org/licenses/by/4.0/.

\section{Literatuur}

1. Niet AG van der, Derickx MH, Jongen-Hermus FJ. Wat studenten geneeskunde kunnen leren van kunst. TSG Tijdschr Gezondheidswet. 2018;96:182-4.

2. Linsen A, Elshout G, Pols D, et al. Education in clinical reasoning: an experimental study on strategies to foster novice medical students' engagement in learning activities. Health ProfEduc. 2018;4:86-96.

3. Perry M, Maffulli N, Willson S, et al. The effectiveness of arts-based interventions in medical education: a literature review. MedEduc. 2011;45:141-8.

4. MukundaN, Moghbeli N, RizzoA, etal. Visual artinstruction in medical education: a narrative review. Med Educ Online. 2019;24:1558657.

5. Bentwich ME, Gilbey P. More than visual literacy: art and the enhancement of tolerance for ambiguity and empathy. BMCMedEduc. 2017;17:200.

6. Croix A de la, Rose C, Wildig E, et al. Arts-based learning in medical education: the students' perspective. Med Educ. 2011;45:1090-100.

7. Jones EK, Kittendorf AL, Kumagai AK. Creative art and medical student development: a qualitative study. Med Educ. 2017;51:174-83.

8. Elbert NJ, Cate TJ ten. Kunstobservatie in het medisch curriculum. Een literatuuronderzoek. Ned Tijdschr Geneeskd. 2013;157:A6015.

9. Koksma JJ, Woezik T van, Bosch S van den, et al. Anders leren kijken en de ander leren zien. Coassistenten en aiossen werken samen met kunstenaars om betere dokters te worden. Ned Tijdschr Geneeskd. 2017;161:D1840.

10. Gowda D, Dubroff R, Willieme A, et al. Art as sanctuary: a four-year mixed-methods evaluation of a visual art course addressing uncertainty through reflection. Acad Med. 2018;93:S8-S13. 11S Association of American Medical Colleges Learn Serve Lead: Proceedings of the 57th Annual Research in MedicalEducation Sessions. 